\title{
Macroeconomic Effects on Development of Sparsely Populated Areas in Public Transport
}

\author{
Jiří Čejka \\ Institute of Technology and Business in České Budějovice \\ Faculty of Technology \\ Department of Informatics and Natural Sciences \\ Czech Republic \\ e-mail: cejka@mail.vstecb.cz
}

\author{
Martin Telecký \\ Institute of Technology and Business in České Budějovice \\ Faculty of Technology \\ Department of Informatics and Natural Sciences \\ Czech Republic \\ e-mail: martin.telecky@volny.cz
}

DOI 10.17818/NM/2018/4SI.14

UDK 330.101.541:656.1/.5

Preliminary communication

Paper accepted: 28. 8. 2018
Summary

Traffic services in public transport rank among the most debated topics in the context of the living in the country. Many foreign and domestic expert studies acknowledge importance of this issue and the fact that the transportation and the related accessibility of the country is a problem even in foreign countries. The main aim of this study is to highlight the differences in traffic services in the Czech Republic as their level is different in every region. Another goal is to describe traffic services provided by the public transport in the size categories of villages in individual regions of the Czech Republic and to compare them with the availability of passenger cars in individual households. Passenger cars are more or less necessary alternative to the public mass transport.

\author{
KEY WORDS \\ microeconomic \\ transport \\ correlations analysis \\ statistic indicators \\ EU
}

\section{INTRODUCTION}

Urban regions and their incorporation in the polycentric settlement systems are being discussed by the expert and political bodies in a number of the European countries and at the pan-European level.

In the event of traffic services provided by the public transportation, we can see a so-called vicious circle of the public mass transport in the country. This circle can be simplified as follows:

- A low population of the serviced settlements results in the low economic efficiency of the transport links, which requires the subsidies from the public funds.

- Efforts in increasing the profitability leads to reducing the low used links, which results in the reduction of the supply and the quality of traffic services. For this reason, some passengers start to use other modes of transport (as a rule, their cars).

- As the population decreases, the profitability of transport links is reduced.

This phenomenon was observed in the country both abroad (e.g. in Great Britain) and in the Czech Republic during the transformation period. As the employment opportunities and higher-tier services continue to be concentrated in the bigger populated areas and the basic services (grocery stores, primary schools, pubs, etc.) are more often placed in the departmental centre of the municipality, the role of traffic services will have the increasing importance. The demand for transportation needed for commuting to satisfy basic daily needs in the country is still growing. Economically, this demand is low, especially in the low populated villages in peripheral regions.
Due to the low demand for transportation, the bus and railway transportations are economically least effective in the areas of very low population. Due to the unavailability of data from individual carriers, this statement is hard to be proved even at the "gross" level of regions. Despite this fact, this statement can be considered valid thanks to a number of regional studies. A notable reduction in the number of public mass transport links was typical mainly in the first half of the nineties. The current period can be characterized as a fragile stabilization of the public transport supply. Many reasons for this stabilization can be found, but the most noteworthy one is the influence of institutional factors [1-10].

\section{METHODOLOGY AND SOURCE OF DATA FOR ASSESSMENT OF THE INFLUENCE OF TRANSPORT ON LOW POPULATED AREAS}

The methodology of the paper is determined with respect to the defined objectives. The first objective of the paper is to find whether the regions with a better level of transport accessibility also show better indicators of the socioeconomic development of the monitored EU regions (Saxony-Anhalt, Mazovia, Ozalj, Vysočina, Modena, South Bohemia, Žilina, Nagykálló). At the same time, our task will be to recognize whether the transport affects the economic development of low populated areas or this development happens independently of the transport. Although the data we will use fail to cover the whole range of the socioeconomic level, they describe relations of a few basic factors of socio-economic dynamics of municipalities, namely the business activity, unemployment, migration balance and 
Table 1 Selected characteristics of monitored areas (2016)

\begin{tabular}{|l|l|}
\hline Total population in centres & 5504176 \\
\hline $\begin{array}{l}\text { Total number of economically active (EA) people in centres } \\
\text { Of that: } \\
\quad \begin{array}{l}\text { Economically active employed people } \\
\text { Unemployed people }\end{array}\end{array}$ & 3414125 \\
\hline $\begin{array}{l}\text { Total number of occupied jobs in centres } \\
\text { Total balance of commuting to work per a set of centres }\end{array}$ & 228098 \\
\hline Share of a set of centres in a total number of selected areas in EU & 3609233 \\
\hline Share of the set of centres in a total number of EA in EU (selected areas) & 590600 \\
\hline Share of the set of centres in a total number of occupied jobs in EU (selected areas) & $60.4 \%$ \\
\hline
\end{tabular}

Source: authors

commuting to work. With respect to the objectives of the paper, the methodology will be based on two fundamental approaches to evaluation of transport factors affecting the socio-economic sphere. First, we will evaluate an overall level of transport accessibility in the selected EU municipalities. If we want to describe accessibility of the centres, it is, logically, the best indicator. Second, we will examine the public mass transport in municipalities as it is the second most important way of how to commute to the selected centres. Traffic services, moreover, allow us to evaluate well the differences at the transport infrastructure level. It also enables us to capture the spatial injustice factor since not all citizens can commute by car and they depend on the public mass transport. Factors of transport accessibility and traffic services will be then compared with socio-economic factors of the EU areas. As an additional research hypothesis, we will verify the assumption of whether the selected peripheral regions of the EU show the worse transport accessibility and traffic services than the development (urbanized) areas [5], [10-15]

Working micro regions were defined based on the above methodology of definition of the micro region working centres. The criteria: at least one municipality (other than a centre) should belong to the micro region and none of micro regions should drop below the limit of 6,000 inhabitants after making partial adjustments. The adjustments were made to allow definition of compact non-perforated regions.

\subsection{Analysis of selected socio-economic indicators}

The quantity analysis of the differentiation of socio-economic indicators in the monitored areas makes it possible to generalize the knowledge obtained from a large volume of data. The application of quantity analyses in the geographical research is, however, associated with many problems and restrictions especially related to a spatial nature of data. First, in analysing the data aggregated into territorial units we cannot exclude the fact that the relations monitored on the population level do not have to apply equally to all areas. The results of spatial statistical analyses considerably depend on the exact definition of the used territorial units and the chosen scale level of monitoring. This phenomenon was very strongly felt in studying of the transport indicators which are, in principle, determined by the definition of the centres of commuting. As far as the socio-economic indicators are concerned, we considered the defined municipalities of EU as one unit and, therefore, determination of nearness of the centre of commuting to work was less notable (perhaps except the share of people leaving the municipality). For the explanatory power of the summary analysis of the economic position of municipalities it is necessary that all indicators within a given analysis are consistent and represent the situation from a similar perspective. The indicators which fail to make this but are important can be used as supplementary in interpreting the results of analysis. In this case, these indicators were the rate of commuting to work and the migration balance [16-25].

The economic position of municipalities was evaluated upon the business activity, the analysis of the labour market and basic demographic data, such as a migration balance and commuting to work from municipalities in the territory under investigation. A few indicators were chosen for the geographical analysis and territorial differentiation in a whole set of monitored areas. Namely, the business activity (a number of registered active economic entities per capita,

Table 2 Selected characteristics of monitored areas (2016)

\begin{tabular}{|l|c|}
\hline Average population in the working micro region & 40164 \\
\hline Average number of economically active people in the working micro region & 17320 \\
\hline Average number of occupied jobs in the working micro region & 17854 \\
\hline Average number of municipalities in the working micro region & 29 \\
\hline Average population in the centres of micro regions & 23201 \\
\hline Average population in the centres of micro regions & 5121333 \\
\hline Average number of economically active people in the centres of micro regions & 10509 \\
\hline Total number of economically active people in the centres of micro regions & 2995487 \\
\hline Average number of occupied jobs in the centres of micro regions & 14109 \\
\hline Total number of occupied jobs in the centres of micro regions & 2785456 \\
\hline
\end{tabular}

Source: authors 
a share of employers in the number of economically active people in the municipality and a share of the number of self-employed persons in the number of economically active people), unemployment rate, tax yield per capita and demographic indicators and a share of people commuting to work outside the municipality in the population of the municipality).The supplementary explanatory factors which we used in factor analyses included the population of municipalities and the number of occupied jobs in micro regional and interregional centres [25-29].

\subsection{Correlation analysis}

The correlation analysis was chosen as a method for determining significance of the relationship of individual transport and socio-economic indicators. The relationship between these quantities can have various intensity - from the full independence ( 0 ) to the full (functional) dependence (1). We want to evaluate the level of dependence of these two random quantities. The level of dependence will be characterized by the level of statistic dependence intensity. The level of significance was chosen as $p=0.05$ If there is a correlation coefficient of a black colour in Tables 3, it means that the level of significance was not achieved $(p \geq 0)$ and no significant relationship between the indicators can be found out. The correlations marked in red are, on the other hand, significant on the level of significance $p<0.05$. Although their correlation coefficient is very weak, certain dependence is apparent on the given level of significance. Given the very high number of compared data, even very weak relations were statistically significant. While in comparing the data on 29 samples the mean dependence may be statistically not significant, in correlating of 2,000 samples the virtually unimportant, unusable relation may be highly statistically significant [25], [30-33].

\section{RESULTS}

First, we created the categories which were then compared using the correlation coefficient. Virtually all compared indicators of the socio-economic level of municipalities, as well as their transport accessibility and traffic services, were categorized. The signs of indicators in Table 3 show the correlation. A positive sign means that the higher the first indicator, the higher will be the second indicator. A negative sign means that the higher the first indicator; the lower will be the second indicator. In case of some indicators, understanding of this relation is basically inverted. For instance, a higher level of transport accessibility in fact means a worse accessibility, as the number of kilometres and minutes needed for commuting to the centre is higher as well as the average speed because an average speed is basically higher on a longer route to the centre. Similarly, a higher average point value of the first arrival at the centre and the last departure from the centre mean a later first arrival of the transport link from the municipality to the centre and the earlier last arrival of the transport link to the municipality. A higher value of the first arrival and the last departure, therefore, means a worse level of traffic services. Although the readers may find it confusing, the data were conceived this way and were not adjusted any more. Only the regional centres where the values of traffic services and accessibility were zero were removed from the data. The reason was that the accessibility to these centres was monitored (departures of transport links were consolidated with respect to deviations among individual monitored areas).

Total resulting relations among the correlation analysis indicators are very weak, except for the relation between the traffic services indicators and the population. Especially the relation between the number of public mass transport links and the population shows the clearly highest level of dependence ( 0.67 on the micro regional level). The influence of transport accessibility on the indicators of socio-economic position is considerably weaker on the interregional level than on the macro regional level. The reason is that we work with a very high number of interregional transfer points. If only the regional towns were among the interregional transfer points, the dependence would be higher. In our concept, the interregional transfer points are basically similar to the micro regional centres. However, the following principle holds true: the better is the level of transport accessibility of the municipality to the interregional centre; the higher is the positive migration balance as well as the number of leaving persons and a share of employers. [33-35]

The problem of this analysis is the fact that we correlate the transport accessibility to the centres with socio-economic indicators of all municipalities from different regions.

Based on the correlation analysis of the above mentioned indicators, we will now try to answer the question asked at the beginning of the project. It was confirmed that the municipalities with a better level of transport accessibility and traffic services show also a better level of region's socioeconomic development indicators in the selected EU areas. The results of correlation analysis of individual indicators confirmed the statistically significant dependence thanks to a large volume of statistical samples. Generally, we can conclude that the better level of transport accessibility and traffic services indicated, in principle, a higher positive level of the migration balance, higher business activity, lower unemployment and a higher share of people leaving for work outside the municipality. It is, therefore, justified to ensure the quality and sufficient public transport in the low populated areas [28], [35], [36].

\section{CORRELATION AND MAP COMPARISON}

In the last analysis we chose the correlation and the map comparison of the selected transport indicators with a comprehensive socio-economic typology of municipalities as per the indicators used in the execution of the RUMOBIL project by all participants. We made a comparison of the average point values of the typology and the transport indicators, specifically the average value of traffic services to the micro- and mezzoregional centres. The typology of the areas under study (selected low-populated areas) was assessed from the viewpoint of the synthesis of indicators of the municipality conditions development and the settlement structure. The typology compares the development features of municipalities also in the context of the settlement conditions and the spatial structure of socio-economic phenomena. The level for the typology definition (types of areas) is determined by the variation range from positive values through the transition zone to the negative values. The positions of territorial units in the indicators values 


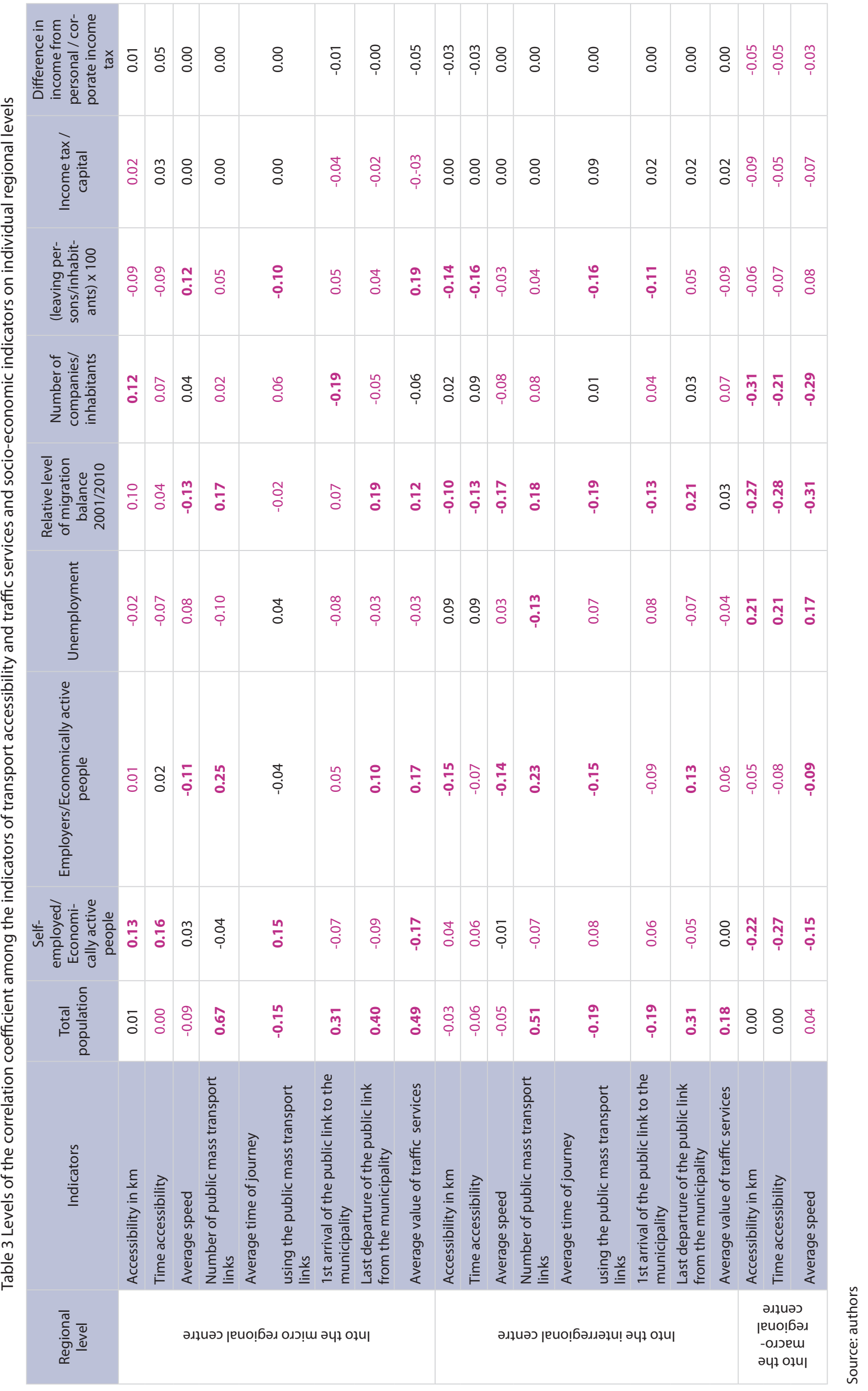


Gross domestic product (GDP) per inhabitant in purchasing power standards (PPS) in relation to the EU-28 average, by NUTS 2 regions, 2015

( $\%$ of the EU-28 average, EU-28 = 100)

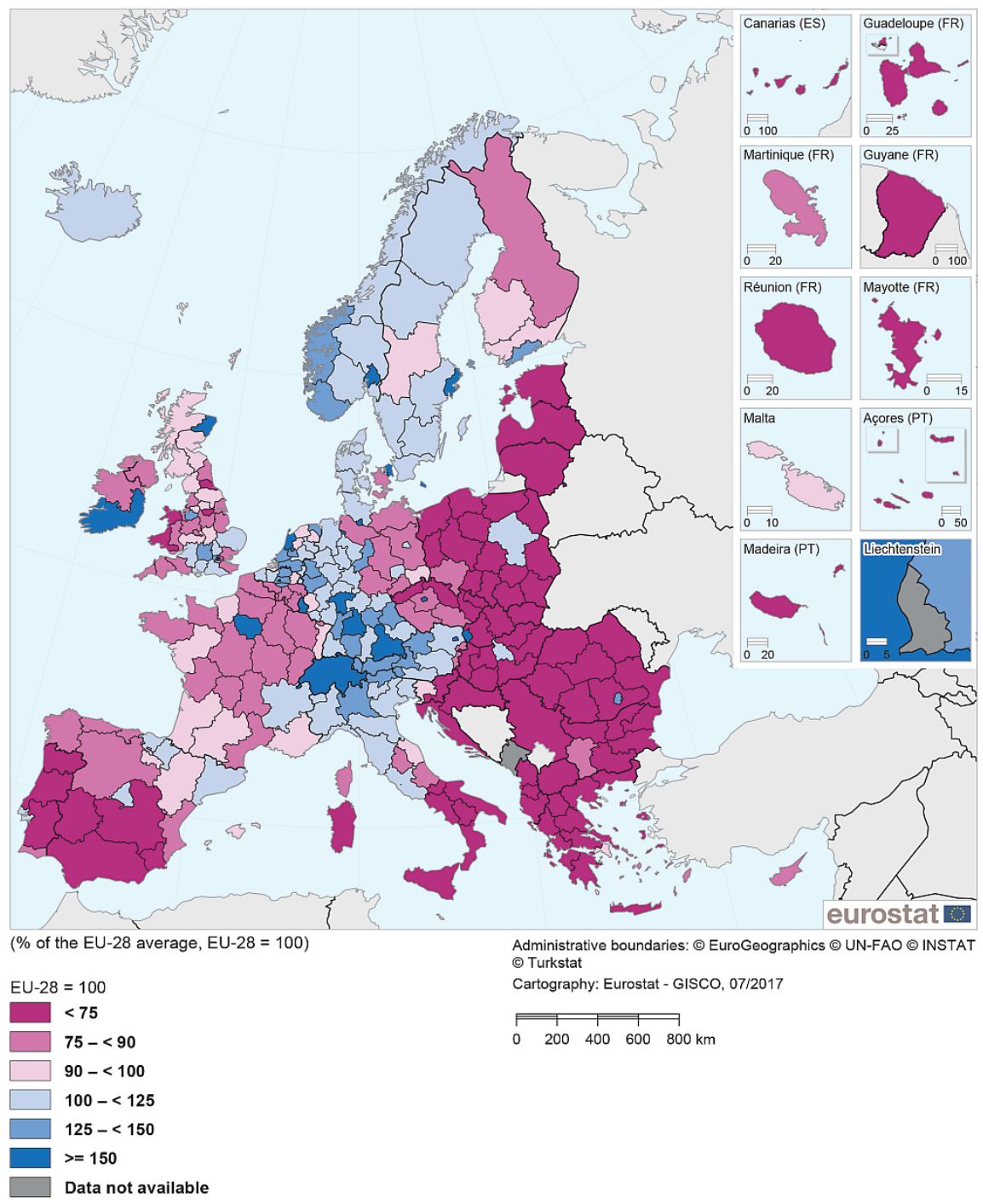

Note. Ireland, Norway and Albania: 2014. Switzerland and Serbia: national data. Switzerland: provisional. Source: Eurostat (online data codes: nama_10r_2gdp and nama_10_pc)

Source: Eurostat

Figure 1 GNP in Regional area EU

were taken from the analysis of partial activities as made by the RUMOBIL project participants [37], [38].

\section{CONCLUSION}

Firstly, we evaluated the correlation of socio-economic indicators among them to determine the relevance of individual socio-economic indicators in other analyses. The number of companies per capita had the highest level of correlation with other indicators. It was followed by the share of employers in economically active people. Also a gross level of migration balance correlated relatively strongly with other indicators, especially the business activity indicators. Unemployment correlated most with a share of leaving persons (the more leaving persons, the lower unemployment). The share of leaving persons reflects the transport accessibility most, except for unemployment, it least represents the other socio-economic indicators.
On the micro regional region, dependences of transport and socio-economic indicators are in the even less close relation than on previous levels. Paradoxically, the indicator of an average level of traffic services shows a higher level of correlation than on the interregional level. The better is the average number of traffic services; the higher is the population of municipality and positive level of migration, the share of employers and the share of leaving persons. On the other hand, unemployment is lower.

The influence of the transport accessibility is rather weaker. The average speed of commuting to the centre, which represents a greater distance from the centre, has the greatest dependence on socio-economic indicators. The higher is the average speed of commuting to the centre (greater distance), the lower is the share of leaving people and the share of employers and self-employed people. On the other hand, the rate of unemployment is higher. In case of other factors of 
transport accessibility, the dependencies are not too clear. Also on the micro regional level, the following principle applies: the better is the (average) level of traffic services and transport accessibility, the higher is the positive level of migration, share of leaving people and business activity (a higher share of employers). Unemployment is lower. The results of some indicators are not, however, clear and, therefore, cannot be overestimated. What is more, the level of the so low correlation is the lowest on the micro regional level.

Based on the analyses made in this Chapter we can conclude that the better the level of public traffic services and, to a lesser extent, the level of transport accessibility of the private motor vehicle transport are, the better the total socioeconomic indicators indicating the development potential and the population density of municipalities are.

\section{Acknowledgement}

The publication was created in connection with the project solution CE 55 - Rumobil

\section{REFERENCES}

[1] Čejka, J., Smetanová, D. Optimization of distribution routes through the Clark-Wright method. In: Khalid S. Soliman. Vision 2020: Innovation Management, Development Sustainability, and Competitive Economic Growth. International Business Information Management Association (IBIMA), 2016. pp. 1195-1207. ISBN 978-0-9860419-8-3.

[2] Behmann, F., Wu, K., Collaborative Internet of Things (C-loT): for Future Smart Connected Life and Business, Wiley, 2015.

[3] Gubbia, J., Buyyab, R., Marusic, S., Palaniswami, M. Internet of Things (IoT): A vision, architectural elements, and future directions. In: Future Generation Computer Systems, 2013, Vol. 29, pp. 1645-1660. https://doi.org/10.1016/j. future.2013.01.010

[4] Ashton, K. That "Internet of Things" thing, RFiD Journal (2009).

[5] Sundmaeker, H., Guillemin P., Friess P., Woelfflé S., Vision and challenges for realising the Internet of Things. In: Cluster of European Research Projects on the Internet of Things-CERP IoT, 2010.

[6] Buckley, J. (Ed.), The Internet of Things: From RFID to the Next-Generation Pervasive Networked Systems, Auerbach Publications, New York, 2006.

[7] Akyildiz, I. F., Su W., Sankarasubramaniam Y., Cayirci E. Wireless sensor networks: a survey, Computer Networks, 2002, Vol. 38, pp. 393-422. https:// doi.org/10.1016/S1389-1286(01)00302-4

[8] Weiser, M., Gold R. The origins of ubiquitous computing research at PARC in the late 1980s, IBM Systems Journal, 1999. https://doi.org/10.1147/ sj.384.0693

[9] Caceres, R., Friday, A. Ubicomp systems at 20: progress, opportunities, and challenges, IEEE Pervasive Computing, 2012, Vol. 11, pp. 14-21. https://doi. org/10.1109/MPRV.2011.85

[10] Atzori, L., lera, A., Morabito, G. The Internet of Things: a survey. Computer Networks, 2010, Vol. 54, pp. 2787-2805. https://doi.org/10.1016/j. comnet.2010.05.010

[11] Sundmaeker, H., Guillemin, P., Friess, P., Woelfflé, S. Vision and challenges for realising the Internet of Things. In: Cluster of European Research Projects on the Internet of Things-CERP IoT, 2010.

[12] Belissent, J. Getting clever about smart cities: new opportunities require new business models, Forrester Research, 2010

[13] Talari, S., Shafie-khah, M., Siano, P., Loia, V., Tommasetti, A., Catalão, J.P.S. A Review of Smart Cities Based on the Internet of Things Concept. In: Energies, MDPI, 2017.

[14] Jaradat, M., Jarrah, M., Bousselham, A., Jararweh, Y., Al-Ayyoub, M. The Internet of Energy: Smart Sensor Networks and Big Data Management for Smart Grid. Procedia Computer Science, 2015, Vol. 56, pp. 592-597. https:// doi.org/10.1016/j.procs.2015.07.250

[15] Whitmore, A., Agarwal, A., Da Xu, L. The Internet of Things-A survey of topics and trends. Information Systems Frontiers, 2015, Vol. 17, Issue 2, pp. 261-274. https://doi.org/10.1007/s10796-014-9489-2
[16] Gogola, M., Veterník, M. The correlation analysis of the public transport passengers and car motorization in city of Martin. Logi - Scientific Journal on Transport and Logistics, 2015, Vol. 6, No. 2, pp. 109-117. ISSN 1804-3216.

[17] Ngai, E. W. T., Moon, K. K. L., Riggins, F. J., Yi, C. Y. RFID research: an academic literature review (1995-2005) and future research directions. International Journal of Production Economics, 2008, Vol. 112, Issue 2, pp. 510-520. https://doi.org/10.1016/j.ijpe.2007.05.004

[18] Zhu, C., Leung, V. C. M., Shu, L.; Ngai, E. C. H. Green Internet of Things for Smart World. In: IEEE Access 2015, Vol. 3, pp. 2151-2162.

[19] Rawat, P., Singh, K.D., Chaouchi, H., Bonnin, J. M. Wireless sensor networks: A survey on recent developments and potential synergies. In: J. Supercomputer. 2014, Vol. 68, pp. 1-48. https://doi.org/10.1007/s11227013-1021-9

[20] Hancke, G., Silva, B., Hancke, G. Jr. The Role of Advanced Sensing in Smart Cities. Sensors, 2012, Vol. 13, pp. 393-425. https://doi.org/10.3390/ s130100393

[21] Zanella, A., Bui, N., Castellani, A., Vangelista, L., Zorzi, M., Internet of Things for Smart Cities. In: IEEE Internet Things J., 2014, Vol. 1, pp. 22-32.

[22] Medagliani, P., Leguay, J., Duda, A., Rousseau, F., Duquennoy, S., Raza, S., Ferrari, G., Gonizzi, P., Cirani, S., Veltri, L., Monton, M., Domingo, M., Dohler, M., Villajosana, I., Dupont, O. Internet of Things Applications-From Research and Innovation to Market Deployment. Bringing IP to Low-Power Smart Objects: The Smart Parking Case in the CALIPSO Project; The River Publisher, Series in Communication: Delft, The Netherlands, 2014, pp. 287-313.

[23] Pike, J.The Internet OfThings And Machine Learning, Moor Insights and Strategy, 2016. Available via: https://www.forbes.com/sites/moorinsights/2016/03/16/ the-internet-of-things-and-machine-learning/\#5b7022123fb1.

[24] Haiyan, L., Song, C., Dalei, W., Stergiou, N., Ka-Chun, S. A remote marker less human gait tracking for e-healthcare based on content-aware wireless multimedia communications, IEEE Wireless Communications, 2010, Vol. 17, pp. 44-50. https://doi.org/10.1109/MWC.2010.5416349

[25] Nussbaum, G., People with disabilities: assistive homes and environments. Computers Helping People with Special Needs, 2006.

[26] Yun, M., Yuxin, B. Research on the architecture and key technology of Internet of Things (IoT) applied on smart grid. Advances in Energy Engineering, ICAEE, 2010, pp. 69-72.

[27] Kumar, P., Ranganath, S., Huang, W., Sengupta, K., Framework for real-time behaviour interpretation from traffic video. IEEE Transactions on Intelligent Transportation Systems, 2005, Vol. 6, pp. 43-53. https://doi.org/10.1109/ TITS.2004.838219

[28] Kampf, R., Stopka, O., Kubasakova, I., Zitricky, V. Macroeconomic Evaluation of Projects Regarding the Traffic Constructions and Equipment. In: Procedia Engineering, Vol. 161, 2016, pp. 1538-1544. World Multidisciplinary Civi Engineering-Architecture-Urban Planning Symposium, WMCAUS 2016; Prague; Czech Republic; 13 June 2016 through 17 June 2016; Code 132600. https://doi.org/10.1016/j.proeng.2016.08.623

[29] Lin, H., Zito, R., Taylor, M. A review of travel-time prediction in transport and logistics. In: Proceedings of the Eastern Asia Society for Transportation Studies, 2005, Vol. 5, pp. 1433-1448.

[30] Mayer-Schönberger, V. Failing to forget the "Drunken Pirate". In: Delete: the Virtue of Forgetting in the Digital Age (New in Paper), first ed., Princeton University Press, 2011, pp. 3-15.

[31] Methodology and indicator calculation method for sustainable urban mobility. World Business Council for Sustainable Development. Project 2.0 (SMP2.0), WBCSD, 2015.

[32] Olaverri-Monreal, C. Autonomous Vehicles and Smart Mobility Related Technologies. Info communications Journal, 2016, Vol 8, pp. 17-24.

[33] ESPON 1.1.2. Urban-rural relations in Europe. Helsinki University of Technology, Helsinki, 2005.

[34] ESPON 1.1.3. Enlargement of the European Union and the wider European perspective as regards its polycentric spatial structure. KTH Stockholm, 2006.

[35] ESPON 1.4.1. Small and medium-sized towns (SMESTO).Österreichisches Institute für Raumplanung, Wien, 2006.

[36] Hall, P., Pain, K. The polycentric metropolis: Learning from mega-city regions in Europe. Earthscan London \& Sterling, VA, 2006.

[37] Maier, K., Mourato, J. Ryser, J. How can polycentricism of territorial development improve functional integration? In: Sharing responsibility for our regions: Redefining the public interest for territorial development. UNECE Conference Bratislava 2006.

[38] Policy of Territorial Development of the Czech Republic. MMR Prague, Czech Republic. 2006. 